Proceedings

\title{
Sequence-Related Amplified Polymorphism (SRAP) Markers: A Feasible Tool for Studies in Invasion Genetics of Freshwater
}

\section{Fish $^{\dagger}$}

\section{Sevan A ̆gdamar}

Citation: Ağdamar, S. SequenceRelated Amplified Polymorphism (SRAP) Markers: A Feasible Tool for Studies in Invasion Genetics of Freshwater Fish. Proceedings 2021, 68, x. https://doi.org/10.3390/xxxxx

Academic Editor:

Received: date

Accepted: date

Published: date

Publisher's Note: MDPI stays neutral with regard to jurisdictional claims in published maps and institutional affiliations.

Copyright: () 2021 by the authors. Submitted for possible open access publication under the terms and conditions of the Creative Commons Attribution (CC BY) license (http://creativecommons.org/licenses/by/4.0/).

\author{
Gökçeada School of Applied Sciences, Çanakkale Onsekiz Mart University, 17760 Çanakkale, Turkey; \\ sevanagdamar@comu.edu.tr; Tel.: +90-286-8872302 \\ + Presented at the 1st International Electronic Conference on Biological Diversity, Ecology and Evolution, \\ 15-31 March 2021; Available online: https://bdee2021.sciforum.net/.
}

\begin{abstract}
Molecular tools can effectively be used in diagnosis, identification, management, and most especially detection of invasion pathways and originations of introduced species. It would provide helpful information for a better conception of the events essential for a successful colonization by comparing genetic differentiation of a species among its native and invasive habitats. PCR-based marker techniques, such as RAPD, AFLP and ISSR have been used for studying genetic diversity, taxonomy and phylogeny of the species, but they are generally used for estimating more limited levels of genetic variation. Although the potential for these molecular markers to generate helpful data, researchers have been suspicious to use them resulting from technical deliminations. A more recently developed molecular marker system, Sequence-Related Amplified Polymorphism (SRAP) is easy, reliable, middle-yield, high-dominant total, and iterative way on genetic variation of different species. Like other molecular markers, SRAPs can also be used for assessing invasion genetics of non-native species and their use to discover variations in genetic structure of native and invasive freshwater fish has been starting common. Depends on the rapidly growing body of the literature, we suggest that the SRAPs could, and should, be applied to the subjects of invasion genetics. The aim of this study was to reveal the potential for SRAP markers in invasion genetics of freshwater fish. Results from SRAP products may prove to be significant for discovery of polymorphism and genetic variation for studies in population genetics of invasive species.
\end{abstract}

Keywords: genetic diversity; polymorphism; invasion; molecular markers; non-native species

\section{Introduction}

Molecular marker systems designed to discover variations at the DNA level has become an significant and spectacular tool for both basic and applied researchs. Because of the rapid growth of various open-access genomic datasets, the improvement of molecular markers, which are involved in potential genes of interest, has become comparatively common. In recent years, several new alternating genetic marker technologies have been improved in the field of molecular biology and genetics, mainly due to rapid expanse in genomic studies. These techniques can be used for many purposes (e.g., to determine genetic diversity, to create linkage maps, to identify hybrids, and gene tagging). Genetic marker systems have many different area of utilizations, including in taxonomy, evolutionary biology, ecology, forensics, disease diagnosis and kinship testing [1]. In recent years, it is also globally known that the conservation of biodiversity should be the one of the urgency of the current international society. Because of their life environment, habitat disruption become a major threat to fish species and currently, according to 2020 IUCN Red List, 4705 fish species are endangered [2]. At this point, genetic characteristics of species play $n$ significant role in survival and in their successful adaptation in response to 
environmental impacts [3]. For this reason, studies on species/population genetics have gained more insights into biodiversity researchs.

Global status of biological invasions become a major problem in current years. Though the topic of bioinvasions became a swiftly developing study area, there are big gaps to be filled in the near term [4]. Invasive species are ranked among the most important threats to the loss of biological diversity [5]. Freshwater resources are of serious concern regarding the current and possible impacts of invasive species because of their high biological diversity and because they realize many demands for a successfully functioning society [6]. Biological diversity of freshwater resources is declining at a significant ratio than terrestrial resources making them a high urgency for conservation and sustainable management [7]. Additionally, unmonitored and uncontrolled invasion attempts cause as consequence the decrease of genetic variation within and between populations. At this juncture, molecular tools have been used to understand invasion genetics in freshwater ecosystems.

The improvement of genetic techniques for molecular analyses has led to a great enhancement in our knowledge of the characteristics of animal genetics. With molecular marker systems, it is possible to explore genetic variation in the entire genome of the species [8]. Various marker systems including RAPDs, RFLPs, AFLPs, microsatellites and mtDNA have been used in population genetics research. Like other marker technologies, sequence-related amplified polymorphism (SRAP) is an effective DNA marker system for genetic diversity analysis particularly in plants and fungi [9]. SRAP markers were developed mainly for Brassica species, but it can be used for genetic diversity analysis in a large spectrum of living species because of the genome sequence information is not required for detection [10]. In this study, we discuss the potential of SRAP markers to use in invasion genetics of freshwater fish.

\section{Background}

Many ecosystems are affected by invasive species and they pose one of the major threats to biological diversity worldwide. Globalisation will inevitably enhance the intentional or unintentional introduction of organisms to new ecosystems, and it is greatly predicted that environmental changes will further increase the threat posed by invasive species. Impacts of this globalisation are evident in most seas and inland waters of the world. To assist control and reduce the impacts of invasive species, researchers need access to knowledge that not only provides an idea of and background to the area, but also keeps them current with the latest research results [11].

Molecular technologies are especially appropriate to reveal historical processes, such as bioinvasions. Genetic approaches enable to determine the organism participated in an invasion and often lead to the perception of cryptic invasions. The findings may have implications for sustainable management of ecosystems [12]. On the other hand, little is known about the genetic structure of newly established populations. The utilization of molecular markers in invasive species allowed recording rapid progress regarding the studies of invasion biology. Molecular markers allow determination of variations or polymorphisms that exist within and between populations for specific regions of DNA. There are different types of DNA-based genetic markers. They are differentiated into two groups based on their detection technique; (1) PCR-based (e.g., RAPD, ISSR, AFLP, mtDNA) and (2) is nonPCR-based (RFLP) markers. PCR-based markers depend on amplification of DNA using the PCR and nonPCR-based markers depend on DNA hybridization. An ideal genetic marker system should be polymorphic, simple, quick and inexpensive. It should provide sufficient resolution of genetic differences and need no prior information about the genome of the species.

Each passing day development of new and specific types of molecular markers makes their significance in understanding the genetic diversity between the same as well as different species. SRAP marker system developed by Li and Quiros [9] have been 
widely used in a various molecular studies based on their simplicity, reliability, efficiency and genome-wide coverage [13].

\section{Methodology}

SRAP technology is easily performed with one time PCR to amplify multiple loci in a genome. Two random primers are involved in reaction mix, which leads to maximum elasticity in primer designing and labelling. There is no restriction on primer combinations. SRAP products fall into a size range of 100 to $1000 \mathrm{bp}$, which can be detected in both agarose and acrylamide gels [10].

These markers were developed in Brassica oleracea to particularly amplify coding regions of the genome with uncertain primers targeting GC-rich exons and AT-rich promoters, introns, and spacers. SRAP primers are 17-18 bases long and composed of core sequences, which are 13-14 nucleotides long. The first 10-11 nucleotides starting at the $5^{\prime}$ end are filler sequences, maintaining no specific formation. These are followed by the sequence CCGG- or -AATT. This core is followed by three random nucleotides at the $3^{\prime}$ end. PCR amplification was performed with the following conditions: for the first 5 cycles, denaturation at $94{ }^{\circ} \mathrm{C}$ for $1 \mathrm{~min}$, primer annealing at $35^{\circ} \mathrm{C}$ for $1 \mathrm{~min}$ and primer extension at $72{ }^{\circ} \mathrm{C}$ for $1 \mathrm{~min}$. For the remaining 35 cycles, annealing temperature is raised to $50{ }^{\circ} \mathrm{C}$ [9].

\section{Results and Discussion}

The scale of colonization has significant genetic outcomes as the amounts and types of genetic variation carried from one place to another can affect the possibility of successful establishment, future dispersion and evolutionary process. In concert with advances in molecular methods for investigate genetic diversity and the development of a rapid growing of evolutionary theory related to evolutionary approaches in colonizing populations, it caused the arise of invasion genetics. Nowadays, through the usage of molecular marker systems, we are in a better by far position to understand the migratory history of invasions and evaluate the importance of genetic bottlenecks and founder effects [14].

The wide range of molecular markers that can simply be used in population genetics is quite common. Molecular markers applied to study genetic variations of freshwater fish include detecting polymorphisms in DNA sequence, the use of DNA hybridization methods to determine RFLPs, or the use of PCR-based technology to reveal polymorphism using RAPD, SSR, or AFLP $[15,16]$. Various molecular markers, each with their own advantages and disadvantages have been identified. For instance, RFLPs can be useful for detecting polymorphisms in the genome. However, this marker needs large amounts of DNA, and is expensive, time-consuming, and hard to optimize [16]. The application of RAPD markers in phylogenetic studies between the distantly related species or genus is a main problem because markers are non-locus specific [17]. Like SSRs, the AFLPs can be optimized. The methodology is somewhat prone to empirical errors like RAPDs, and its cost and time required are prevents to its broader approval by the scientific environments [18]. At this point, SRAPs have demonstrated the talent to detect genetic variation at a several of taxonomic levels, and are also often used for molecular analyses of within and between populations [19].

Various comparative works have found SRAPs provide a better levels of variation to other markers, but with considerably less experimental effort and cost for preferable levels of polymorphism and reproducibility [9,20-22]. In this respect, SRAP markers can also be used for understanding invasion genetics of freshwater species and their use to explore variations in genetic characteristics of native and non-native freshwater fish has been starting common. For instance, researchers used SRAPs to differentiate cultured populations in grass carp Ctenopharyngodon idella [23]. They identified eight SRAP fragments that high similarities to functional genes. More recently, scientists tested ISSRs and SRAPs for genetic characterization of invasive populations of gibel carp Carassius gibelio [24]. Both markers showed that gene flow level among populations is low and that genetic 
differentiation level is high. The results also indicate that the existence of invasive populations of gibel carp is the result of several introduction events originating from different sources. Consequently, SRAP markers can successfully determine genetic diversity and find out the origin and distribution of invasive species, such as introduced freshwater fish.

\section{Conclusions}

Although early recognition of the potential benefits of genomic tools for studying biological invasions, the improvement of molecular technologies and resources for invasive species has been lagged [25]. Various molecular marker systems and constantly improving experimental approaches have been developed to reveal the invasion histories. In consequence of this developments, SRAP markers could, and should, be applied in studies on population genetics of invasive species. Findings from SRAP products may prove to be significant for investigation of polymorphism and improvement of new variable loci for investigations in invasion biology.

\section{Abbreviations}

The following abbreviations are used in this manuscript:

$\begin{array}{ll}\text { AFLP } & \text { Amplified fragment length polymorphism } \\ \text { ISSR } & \text { Inter simple sequence repeats } \\ \text { mtDNA } & \text { Mitochondrial DNA } \\ \text { PCR } & \text { Polymerase chain reaction } \\ \text { RAPD } & \text { Random amplification of polymorphic DNA } \\ \text { RFLP } & \text { Restriction fragment length polymorphism } \\ \text { SRAP } & \text { Sequence related amplified polymorphism } \\ \text { SSR } & \text { Simple sequence repeats }\end{array}$

\section{References}

1. Poczai, P.; Varga, I.; Laos, M.; Cseh, A.; Bell, N.; Valkonen, J.P.T.; Hyvönen, J. Advances in plant gene-targeted and functional markers: a review. Plant Methods 2013, 9, 6 .

2. IUCN. The IUCN Red List of Threatened Species. Version 2020-3. 2020. Available online: https://www.iucnredlist.org/resources/summary-statistics (accessed on 27 February 2021).

3. Karr, J.R.; Soule, M.E.; Wilcox, B.A. Conservation Biology: An Evolutionary-Ecological Perspective. J. Wildl. Manage 1981, 420422.

4. Leppäkoski, E.; Gollasch, S.; Olenin, S. Introduction: alien species in European waters. In Invasive Aquatic Species of Europe: Distribution, Impacts and Management; Leppäkoski, E., Gollasch, S., Olenin, S., Eds.; Kluwer Academic: Dordrecht, The Netherlands, 2002.

5. Pimentel, D.; Lach, L.; Zuniga, R.; Morrison, D. Environmental and economic costs of nonindigenous species in the United States. Bioscience 2000, 50, 53-65.

6. Pusey, B.J.; Arthington, A.H. Importance of the riparian zone to the conservation and management of freshwater fish: A review. Mar. Freshw. Res. 2003, 54, 1-16.

7. Vörösmarty, C.J;; McIntyre, P.B.; Gessner, M.O.; Dudgeon, D.; Prusevich, A.; Green, P.; Glidden, S.; Bunn, S.E.; Sullivan, C.A.; Liermann, C.R.; Davies, P.M. Global threats to human water security and river biodiversity. Nature 2010, 467, 555-561.

8. Liu, Z.J.; Cordes, J.F. DNA marker technologies and their applications in aquaculture genetics. Aquaculture 2004, 238, 1-37.

9. Li, G.; Quiros, C.F. Sequence-related amplified polymorphism (SRAP), a new marker system based on a simple PCR reaction: Its application to mapping and gene tagging in Brassica. Theor. Appl. Genet. 2001, 103, 455-461.

10. Li, G.; McVetty, P.B.; Quiros, C.F.; Andersen, S.B. SRAP Molecular Marker Technology in Plant Science. In Plant Breeding from Laboratories to Fields; Sven Bode Andersen, IntechOpen: 2013.

11. Ziska, L.H.; Dukes, J.S. Invasive Species and Global Climate Change; CAB International: Wallingford, UK, 2014.

12. Müller, J.C.; Griebeler, E.M. Genetics on Invasive Species. In Invasive Aquatic Species of Europe. Distribution, Impacts and Management; Springer: Dordrecht, The Netherlands, 2002.

13. Robarts, D.W.H.; Wolfe, A.D. Sequence-Related Amplified Polymorphism (SRAP) Markers: A Potential Resource for Studies in Plant Molecular Biology. Appl. Plant Sci. 2014, 2, 1400017.

14. Pearse, D.; Holmlund, H.; Herman, J.; Grove, S.; Winnikoff, J.; Tanner, K.; Sianta, S.; Macias, N.; Vershinina, A. Invasion Genetics: The Baker and Stebbins Legacy; Barrett, S.C., Colautti, R.I., Dlugosch, K.M., Rieseberg, L.H., Eds.; Wiley: Hoboken, NJ, USA, 2017. 
15. Vos, P.; Hogers, R.; Bleeker, M.; Reijans, M.; Lee, T. Van De; Hornes, M.; Friters, A.; Pot, J.; Paleman, J.; Kuiper, M.; Zabeau, M. AFLP: A new technique for DNA fingerprinting. Nucleic Acids Res. 1995, 23, 4407-4414.

16. Williams, J.G.K.; Kubelik, A.R.; Livak, K.J.; Rafalski, J.A.; Tingey, S. V. DNA polymorphisms amplified by arbitrary primers are useful as genetic markers. Nucleic Acids Res. 1990, 18, 6531-6535.

17. Karp, A.; Seberg, O.; Buiatti, M. Molecular techniques in the assessment of botanical diversity. Ann. Bot. 1996, 78, 143-149.

18. Mehboob-ur-Rahman, Zafar Y.; Paterson A.H. Gossypium DNA Markers: Types, Numbers, and Uses. In Genetics and Genomics of Cotton. Plant Genetics and Genomics: Crops and Models; Paterson A.H. Ed.; Springer: New York, NY, USA, 2009.

19. Hale, A.L.; Farnham, M.W.; Nzaramba, M.N.; Kimbeng, C.A. Heterosis for horticultural traits in Broccoli. Theor. Appl. Genet. 2007, 115, 351-360.

20. Levi, A., Thomas, C.E. DNA markers from different linkage regions of watermelon genome useful in differentiating among closely related watermelon genotypes. HortScience 2007, 42, 210-214.

21. Liu, L.; Zhu, X.; Gong, Y.; Song, X.; Wang, Y.; Zhao, L.; Wang, L. Genetic diversity analysis of radish germplasm with RAPD, AFLP and SRAP markers. Acta Hortic. 2007, 760, 125-130.

22. Wang, Y.; Sun, X.; Tan, B.; Zhang, B.; Xu, L.A.; Huang, M.; Wang, M. A genetic linkage map of Populus adenopoda Maxim. $\times$ P. alba L. hybrid based on SSR and SRAP markers. Euphytica 2010, 173, 193-205.

23. Ding, W. Dong; Cao, Z. ming; Cao, L. ping. Molecular analysis of grass carp (Ctenopharyngodon idella) by SRAP and SCAR molecular markers. Aquac. Int. 2010, 18, 575-587.

24. Ağdamar, S.; Baysal, Ö.; Yıldız, A.; Tarkan, A.S. Genetic differentiation of non-native populations of Gibel Carp, Carassius gibelio in Western Turkey by ISSR and SRAP markers. Zool. Middle East. 2020, 66, 302-310.

25. Basu, C.; Halfhill, M.D.; Mueller, T.C.; Stewart, C.N. Weed genomics: New tools to understand weed biology. Trends Plant Sci. 2004, 9, 391-398. 